\title{
To Promote the Development of Teachers' Teaching Beliefs from Reflective Teaching
}

\author{
Zhaohao Nian \\ Faculty of Education, Palacky University, Olomouc, Czech Republic \\ Email: zhaohao.nian02@upol.cz
}

How to cite this paper: Nian, Z. H. (2020). To Promote the Development of Teachers' Teaching Beliefs from Reflective Teaching. Open Journal of Social Sciences, 8, 120-126. https://doi.org/10.4236/jss.2020.811012

Received: October 11, 2020

Accepted: November 10, 2020

Published: November 13, 2020

Copyright ( 2020 by author(s) and Scientific Research Publishing Inc. This work is licensed under the Creative Commons Attribution International License (CC BY 4.0).

http://creativecommons.org/licenses/by/4.0/

\begin{abstract}
With the development of a pluralistic society and the arrival of a lifelong education society, the whole society's expectation for the development of education has become more and more. Therefore, the educational expectation from society is undoubtedly a significant challenge to the professional development of teachers. Teachers' professional development means the development of a teacher's personal, professional life, including the enhancement of confidence, skills, and knowledge. The knowledge of the subject taught is continuously updated, broadened, and deepened (Hoyle \& Megarry, 2016). Teachers' professional development is the accumulation of knowledge and skills and the system of teachers' thinking, values, and beliefs. Encouraging teachers to reflect on teaching and improving their reflective ability can stimulate teachers' sense of teaching efficacy and enable teachers to examine their teaching behaviors and ideas systematically. Teachers as the source of knowledge transfer and initiator, their beliefs in time, and the dynamic teaching process gradually accumulate. The novice teachers are flexible to use diverseteaching methods to be professional teachers in reflecting on the teaching and the long-term accumulation of reflective teaching has become a new angle of view to review the professional development of teachers' beliefs.
\end{abstract}

\section{Keywords}

Social Expectation, Teaching Reflection, Teaching Beliefs

\section{Introduction to Reflective Teaching}

Dewey defined reflection as presumptive knowledge with sustained and deliberate beliefs. According to Dewey, reflection is different from thinking because thinking is born, and reflection should be a learned skill and habit (Edwards, 1965). Reflection does not mean thinking about a problem. It has a broader 
meaning than thinking: it is a recursive process involving actions (experience) and reactions (reflection), then action (experiment), and then reflection. On the other hand, Schön believes that reflection is a process in which teachers always acquire some new knowledge from special situations and uncertain situations in teaching (Schön, 1992). The method of acquiring new knowledge is reflection. Two forms of personal reflection: reflection after action and reflection in action. Post-action reflection means that the individual reflects on the action after the end of the action, while the reflection in action emphasizes that the action should be reflected at the same time, and the reflection and action should happen at the same time. Killion and Todnem extended Schon's reflection model by adding "reflection for action". This reflection is based on past thoughts and actions and leads to future actions (Killion \& Todnem, 1991). The specific application methods of reflective teaching include diary-keeping, listening to lectures and observation, teacher's evaluation, teaching behavior research, etc. The objects of reflection are extensive. In addition to teachers' teaching actions, teaching objectives and teaching means, traditional habits, common sense, and other people's teaching methods can all be the objects of reflection.

\section{Introduction to Teacher's Beliefs}

Teachers' beliefs, that is, the inherent and lasting concept held by themselves, are rich and diversified in content. A teacher's belief's specific contents can be divided into five aspects from different angles: decision-making basis belief, preference belief, personal self-belief and teacher's self-belief, belief of educational purpose and belief of professional goal realization method. Teachers' beliefs can be divided into teaching efficacy, epistemological belief, achievement motivation, self-perception, self-efficacy, and other aspects (Zeichner et al., 1996). Teachers' belief-system includes beliefs in the teaching process, beliefs in teachers' roles, beliefs in discipline and self-learning, beliefs in the learning environment and teaching mode.

\section{Introduction to Teacher's Teaching Beliefs}

Teaching beliefs are defined as teachers' views and comprehensions about teachers teaching knowledge. The teachers' teaching beliefs would influence the understandings about instructional theory and teaching experiences, and the teaching plan ever controls the teaching behaviors. Teacher's teaching beliefs determine and influence their classroom practices, as well as influence the teacher's professional development (Schutz et al., 2020). Therefore, teachers should become more self-aware of their beliefs and realize that their actions and their interactions form part of every individual learner's construction of knowledge.

\section{Methodology}

This paper illustrates that the reflection on teaching can be a perspective to review the teachers' beliefs (Newby, 2010). During the overall process, qualitative 
methodology is adopted in this study, mainly analyzes the internal relation between reflection on teaching and teachers' beliefs and impacts. From the perspective of reflection on teaching to review and connect with current status on teaching and the teacher's belief in professional development, using the qualitative research method, this paper probes into the necessity of correct reflective teaching to teachers' belief from the angle of academic theory.

\section{The Theoretical Framework}

\subsection{Equal Rationalization of Practice}

The rationalization of way is embodied in the interpretation of teaching practice from the existing perspective so that behavior and results are rationalized. Its essence is to dominate the practice with the inherent concept, which is reflected in the form. Its goal is to prove the correctness of the original views with the post-evaluation and conclusion. Its result is to cover the existing practice in teaching (Larson, 2014). For example, if a teacher makes a judgment that a student is not interested in learning, this view will probably lead the teacher to attribute the inefficiency of classroom learning to the students' attitude and ignore the influence on the students' attitude.

\subsection{Equate Experience}

Experience plays a vital role in teacher development, but the foundation of teacher professional growth is not to experience itself. The accumulation of experience is only the first step to professional growth. Systematic knowledge and skills must be acquired through reflection and experience (Meads \& Meads, 2001). The lack of reflective experience is likely to lead to the recurrence of similar problems in teaching, and the knowledge and value outlook acquired by teachers are likely to remain on the surface, unable to form regular cognition, and lack of guiding significance for new situations and new problems in the future. Subconsciously using immobilized teaching methods and strategies by experience will not achieve the educational goal of individualized teaching and hinder the effective professional development of teachers. The key to the positive or negative transfer of teachers' beliefs is not the length of teaching experience but the effectiveness and depth of reflective teaching. Reflection is not equal to the ability to explain the reasonableness of teaching, nor is it similar to the natural accumulation of experience.

\subsection{Holistic Thinking}

The teacher's attribution dimension and attribution method is an important part of reflection, which significantly affects the development of the teacher's beliefs. When teachers entirely attribute the problems in teaching to their ability, they will have negative emotions of tension and fear, and their sense of self-efficacy will be reduced accordingly, thus affecting the overall teaching belief. However, if the teacher attributes the teaching problem to encounter such kind of students 
is their bad luck, or this problem is a pure accident, etc, it will neither generate fluctuating emotions nor make any adjustment to the teaching behavior. The belief of the teacher is not challenged, so the beliefs of the teacher will gradually solidify. Enrich the reflective dimension not only pays attention to the achievement of class students but also pays attention to students' individual needs (Levy, 2018).

\subsection{Enrich Metacognition}

To realize the self-renewal and sustainable development' importance, teachers' metacognition level could be improved. It is not only necessary to constantly learn new subject knowledge, try to adopt new teaching strategies, improve teaching skills and enrich teaching experience, but also necessary to self-regulate and self-monitor one's cognition (Metcalfe, 1998). That is to say, in the process of teaching practice, teachers should not only determine the teaching situation, the teaching plan and method to make a choice, to know their own level of ability of teaching and students' cognitive differences, and to analyze the cognitive process of self, will own teaching thoughts and teaching ideas, as compared with the objective reality and ongoing self-feedback, from finding problems, to analyze problems, to adjust yourself, find a more reasonable solution. Metacognition is the basis of reflection activities. Teachers with metacognitive awareness and strategies can actively think about the causes and possible results of their self-behaviors in the early stage of teaching and objectively and scientifically examine each step of their actions. Such teachers can infiltrate reflection into every link of teaching and learning, truly realize "reflection for action", avoid the cycle of self-certification of teachers' beliefs, and realize the professional development of teachers' beliefs in reflection.

\subsection{Collaborative Reflection}

The implementation of reflective teaching requires teachers' strong critical spirit and self-reflection consciousness and a good collection, the teaching and research atmosphere of cooperation and reflection (Nicholls, 1997). The first reason to emphasize cooperative reflection is to avoid the "self-consistency" of individual beliefs, individuals protect their beliefs from attack by rationalizing their behaviors, thus forming a self-argument and self-styled; Secondly, critical spirit and reflective ability need long-term cultivation. The appropriate frequency of collective discussion and common analysis is conducive to forming a collective atmosphere for reflection and development and forming a reflective teaching model of mental and behavioral model in the collaborative discussion and mutual stimulation.

\section{Mind Map}

Researchers generally believe that people's core beliefs are constant. As a stable system, belief systems have a lot of mutual acceptance and interconnected be- 
liefs. People tend to use evidence of cognitive skills and self-perception conflicts to support their existing beliefs, even if the evidence base may be completely unreliable. This process occurs not only because people's emotional traits interfere with cognition out of a self-protective instinct, but also because the cognitive information processing system itself is based on people's beliefs (Russell \& Korthagen, 1995) (as shown in Figure 1).

However, beliefs are not set in stone. Piaget's assimilation and hue theory to describe how human cognition processes by new information. When existing beliefs conflict with real problems, individuals have doubts about existing beliefs, and new beliefs are reasonable and effective, replacement and update of belief system will occur (Geber, 2006). In the process of teacher's growth, the teacher's belief system is not closed and invariable but open. With the change of the external environment and teachers' practical experience, teachers' beliefs will be adjusted, enriched, and improved. Through interviews with teachers, it is found that the change of belief is influenced by the individual's living conditions, educational practice, and social culture. The ups and downs of personal circumstances, the impact of educational reform, the innovation of social concepts, and teachers' teaching experience are all the sources of the renewal of teachers' faith. Teachers' beliefs are more likely to change when they interact with students, society, and the environmental educational environment, have a high sense of efficacy, and actively carry out self-reflection and evaluation (Loughran, 1996). This can help us understand how the teaching and reflection interact and how the teacher's belief develops and teacher career development changes (as shown in Figure 2).

\section{Conclusion}

Firstly, teachers should be rated and comprehensive, and they need to realize

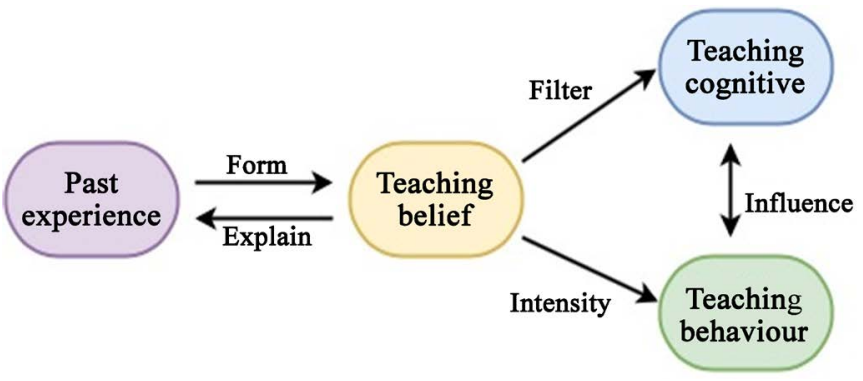

Figure 1. Processing system.

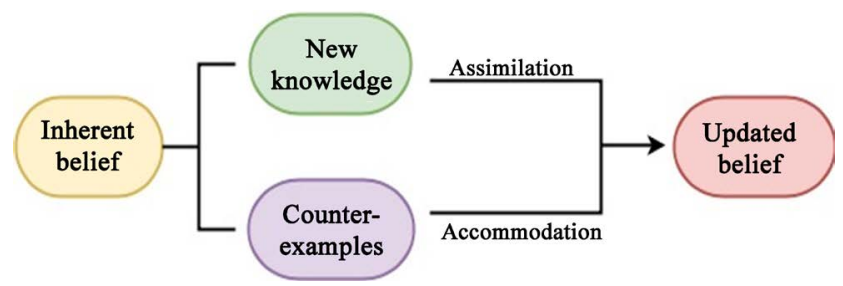

Figure 2. Updated process. 
that teaching is a complex dynamic process. Each link is related to and influenced by each other. Reflection can be able to abstract and filter experience, to a certain extent, to eliminate the unreasonable or invalid elements of experience and help to build the body's knowledge and belief system. Secondly, new ideas should be viewed with an open mind to inspire the renewal of teachers' beliefs; new information should be constantly received, and existing teaching decisions should be carefully considered. Each teacher's unique ideas and theories should be respected about student development, teaching management, and teachers' role. These ideas and theories determine teachers' self-regulation, the way of teacher-student interaction, and evaluation methods. Thirdly, the most essential qualities for the cultivation of reflective quality are concentration, openness, and a sense of responsibility. In teaching, teachers try to reflect correctly and rationally before and after instruction, which is also a positive factor in helping teachers complete their professional development and accumulate positive professional development of teacher beliefs.

\section{Conflicts of Interest}

The author declares no conflicts of interest regarding the publication of this paper.

\section{References}

Edwards, A. (1965). The Dewey School. New York: Routledge. https://doi.org/10.4324/9781315131733

Geber, B. (Ed.) (2006). Piaget and Knowing. London: Routledge. https://doi.org/10.4324/9780203715772

Hoyle, E., \& Megarry, J. (Eds.) (2006). World Yearbook of Education 1980. London: Routledge. https://doi.org/10.4324/9780203080511

Killion, J., \& Todnem, G. (1991). A Process for Personal Theory Building. Educational Leadership, 48, 14-17. https://eric.ed.gov/?id=EJ422847

Larson, J. (2014). Radical Equality in Education. New York: Routledge. https://doi.org/10.4324/9780203118672

Levy, M. (2018). A Holistic Approach to Lessons Learned. New York: Auerbach Publications. https://doi.org/10.1201/9781351235549

Loughran, J. (1996). Developing Reflective Practice. London: Routledge. https://doi.org/10.4324/9780203453995

Meads, G., \& Meads, T. (2001). Trust in Experience. London: CRC Press. https://doi.org/10.1201/9781315385334

Metcalfe, J. (Ed.) (1998). Metacognition. New York: Psychology Press. https://doi.org/10.4324/9781315799278

Newby, P. (2010). Research Methods for Education. London: Routledge. https://doi.org/10.4324/9781315834627

Nicholls, G. (1997). Collaborative Change in Education. London: Routledge. https://doi.org/10.4324/9781315041872

Russell, T., \& Korthagen, F. (Eds.) (1995). Teachers Who Teach Teachers. London: Rout- 
ledge. https://doi.org/10.4324/9781315043159

Schön, D. (1992). The Reflective Practitioner. London: Routledge. https://doi.org/10.4324/9781315237473

Schutz, P., Hong, J., \& Cross Francis, D. (2020). Teachers' Goals, Beliefs, Emotions, and Identity Development. New York: Routledge. https://doi.org/10.4324/9780429456008

Zeichner, K., Zeichner, K., Liston, D., \& Liston, D. (1996). Reflective Teaching. New York: Routledge. https://doi.org/10.4324/9780203822289 